\title{
Surface Engineering of the RNA Coliphage Q $\beta$ to Display Plasmodium Falciparum Derived Asexual Blood Stage Antigens UB05 and Merozoite Surface Protein 3
}

Alain Bopda Waffo ${ }^{1,2,3^{*}}$, Abel Lissom ${ }^{4,5}$, Herve F. Ouambo ${ }^{4,6}$, Loveline N. Ngu , $^{4,7}$, Apeh A. Ngoh ${ }^{4,8}$, Carrie A. Sanders ${ }^{1}$, Swapnil Bawage ${ }^{1,2}$, Colince J. Tchadji ${ }^{4,5}$, Jules N.C. Assob ${ }^{6}$, Arinze S. Okoli ${ }^{9}$, Doline Takoua ${ }^{10}$, Georgia Ambada ${ }^{4,5}$, Ghislain D. Njambe Priso ${ }^{4,5}$, Rosario Garcia ${ }^{11}$, Anna Gutiérrez ${ }^{11}$, Dieudonné Ndjonka ${ }^{10}$, George O. Chukwuma ${ }^{4,12}$, Malachy I. Okeke ${ }^{13}$, Rosette Megnekou ${ }^{5,14}$, Charles O. Esimone ${ }^{15}$, Eric A. Achidi ${ }^{6}$, Wilfred N. Mbacham ${ }^{4,14,16}$, Lazare Kaptue $^{17}$, Chae Gyu Park ${ }^{18,19}$ and Godwin W. Nchinda ${ }^{20^{*}}$

${ }^{1}$ Department of Biological Sciences/College STEM 1627 Hall Street Montgomery, AL, USA

${ }^{2}$ Center for Nano Biotechnology Research, 1627 Harris Way Montgomery, AL, USA

${ }^{3}$ Microbiology Program, Department of Biological Sciences, College of Science, Technology, Engineering and Mathematics, Alabama State University, Montgomery, AL, USA

${ }^{4}$ Laboratory of Vaccinology/Biobanking, CIRCB Cameroon

${ }^{5}$ Department of Animal Biology and Physiology, University of Yaoundé I, Cameroon

${ }^{6}$ Department of Medical Laboratory Sciences, University of Buea, Cameroon

${ }^{7}$ Department of Biochemistry, University of Yaoundé I, Cameroon

${ }^{8}$ Department of Biomedical Sciences, University of Dschang, Cameroon

${ }^{9}$ Gen $\varnothing k$ - Centre for Biosafety, Tromsø, Norway

${ }^{10}$ Department of Biomedical Laboratory Sciences, University of Ngaoundéré, Cameroon

${ }^{11}$ Centre de Santé Catholique de Bikop, Cameroon

${ }^{12}$ Department of Medical Lab Sciences; Nnamdi Azikiwe University, Awka Nigeria

${ }^{13}$ Molecular Inflammation Research Group, Department of Medical Biology, Faculty of Health Sciences, UiT The Arctic University of Norway, N-9037 Tromsø, Norway

${ }^{14}$ The Biotechnology Center, University of Yaoundé I, Cameroon

${ }^{15}$ Department of Pharmaceutical Microbiology and Biotechnology, Nnamdi Azikiwe University Awka, Nigeria

${ }^{16}$ The Department of Biochemistry and Physiology, Faculty of Medicine, University of Yaoundé I, Cameroon

${ }^{17}$ Université des Montagnes, Bangangté, Cameroon

${ }^{18}$ Laboratory of Immunology, Brain Korea 21 PLUS Project for Medical Science, Severance Biomedical Science Institute, Yonsei University College of Medicine, Seoul 03722, Republic of Korea

${ }^{19}$ Laboratory of Cellular Physiology and Immunology and Chris Browne Center for Immunology and Immune Diseases, Rockefeller University, New York, NY 10065, USA ${ }^{20}$ Department of Biochemistry, University of Dschang, Cameroon

"Corresponding author: Alain Bopda Waffo, Microbiology Program, Department of Biological Sciences, College of Science, Technology, Engineering and Mathematics, Alabama State University, Montgomery, AL, USA, Tel: (001) 334229 8396; Fax: (001) 334229 1007; E-mail: abopdawaffo@alasu.edu and

Godwin W. Nchinda, Laboratory of Vaccinology/Biobanking, CIRCB, Cameroon, Tel: (237) 222315450; Fax: (237) 222315456; E-mail: nsehleseh@gmail.com

Received date: Aug 8, 2018; Accepted date: Aug 16, 2018; Published date: Sep 03, 2018

Copyright: (2018 Wafoo, et al. This is an open-access article distributed under the terms of the Creative Commons Attribution License, which permits unrestricted use, distribution, and reproduction in any medium, provided the original author and source are credited.

\section{Abstract}

Background: Naturally acquired immune responses to Plasmodium falciparum merozoite surface protein 3 (MSP3) and UB05 are implicated in semi immunity in populations living in malaria endemic areas. Thus designing chimeric malaria vaccine candidates involving MSP-3 and UB05 displayed upon the surface of a phage in its native form could potentiate their immunogenicity and antigenicity. In this study, we have engineered both MSP3 and UB05 upon the $Q \beta$ and assessed their antigenicity with plasma from children living in a high malaria transmission region of Cameroon.

Methods: The surface of the RNA coliphage $Q \beta$ was genetically modified to display three Plasmodium falciparum derived immunogens including MSP3, UB05 and a chimera of the two UB05-MSP3. The resultant recombinant

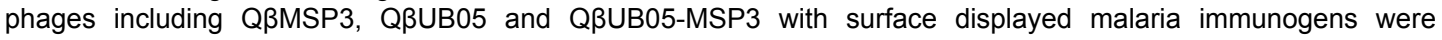
produced after transformation of the $E$. coli strain HB101. Plasma levels of antigen specific IgG antibody were then determined in samples from malaria positive and negative children living in a high malaria transmission region of Cameroon.

Results: To improve yield each recombinant phage was scaled up to $10^{14} \mathrm{pfu} / \mathrm{ml}$ using production strategies previously optimized in our group. This was significantly higher $(P<0.001)$ relative to the $10^{8} \mathrm{pfu} / \mathrm{ml}$ of the wild type 
Citation: Waffo AB, Lissom A, Ouambo HF, Ngu LN, Ngoh AA, et al. (2018) Surface Engineering of the RNA Coliphage Q $\beta$ to Display Plasmodium Falciparum Derived Asexual Blood Stage Antigens UB05 and Merozoite Surface Protein 3. Clin Microbiol 7: 314 . doi: $10.4172 / 2327-5073.1000314$

Page 2 of 10

\begin{abstract}
phage when produced routinely. Conformational integrity of the surface displayed antigens was confirmed in ELISA assays by testing for the specific recognition of the $\mathrm{N}$ and C-terminal parts of both UB05 and MSP3 using the

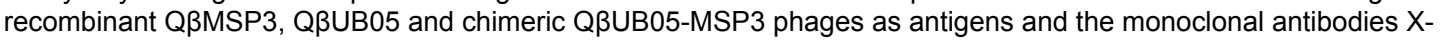
Q38G73-N, X-Q0KGH2-N, X-Q38G73-C, X-Q0KGH2-C targeting the N- and C-terminals of both UB05 and MSP3 respectively. Antigen specific naturally acquired $\lg G$ antibodies in plasma from both malaria negative and positive children living in a high transmission area of Cameroon recognized all three recombinant phages. However, plasma from children less than five years old contained significantly less plasma levels of antigen specific IgG antibodies.
\end{abstract}

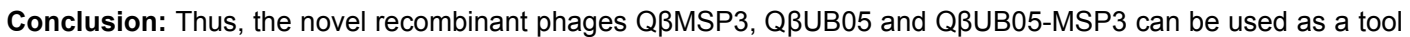
for assessing natural or vaccine-induced antibody responses against malaria. The recombinant chimeric QBUB05MSP3 phage is validated as a multivalent antigen for tracking semi immunity to malaria.

Keywords: MSP3; UB05; UB05-MSP-3; RNA Coliphage Q $\beta$; Antigenicity; Hyper endemic and children

\section{Abbreviation: \\ MSP3: Merozoite surface protein 3; P. falciparum: Plasmodium falciparum; EBA140: Erythrocyte binding antigen 140; Rh2: Rhoptry proteins 2; AU: Arbitrary units; MOI: Multiplicity of infection; LLIN: Long lasting insecticide; IQR: Interquartile range; CNBR: Center for Nano Biotechnology Research; 3D: Three-dimensional; BSA: Bovine serum albumin}

\section{Introduction}

Concerted global efforts have resulted into a significant reduction in morbidity and mortality due to malaria. However the threat due to this ancient scourge remains unrelenting as an estimated 216 million cases and 455000 deaths were recorded in 2016 (World health organization, 2016). Malaria caused by Plasmodium falciparum (P. falciparum) is the most common and virulent form of the disease especially in sub Saharan Africa where most of the global casualties are recorded in children and pregnant women [1]. Current strategies to eradicate the disease are being limited by several factors including parasite genetic diversity, resistance of vector to insecticide and parasite to drug therapies [2-4]. This has resulted too many regions of malaria endemic countries maintaining perennial high malaria transmission zones with consequent significantly high illness burden. Persistent high disease burden within these populations makes developing an effective malaria vaccine the only viable option to stem out the disease.

The recently approved malaria vaccine Mosquirix which induces sporozoites specific antibodies to prevent the malaria parasite from infecting the liver $[5,6]$ though limited in efficacy $[7,8]$ provides a basis upon which to further improve the efficacy of a global vaccine against malaria. In addition, high concentrations of asexual stage antigen specific antibodies have been associated with substantial reduction of parasitaemia and clinical symptoms thereby high lighting their importance in semi immunity to malaria [9]. This makes asexual blood stage malaria vaccines desirable objectives for eliminating clinical malaria. Since long term inhabitants of malaria endemic countries acquire protection from symptomatic malaria following repeated exposure to the malaria parasite $[10,11]$ there is need to also probe these immune responses for correlates of resistance to malaria.

Previously antibodies targeting several asexual stage antigens including the merozoite surface antigens 1 (MSP1) and 3 (MSP3), microneme proteins erythrocyte binding antigen 140 (EBA140) and 175 (EBA175) and rhoptry proteins 2 (Rh2), 5 (Rh5) and UB05 are reported to protect children (5-14 years) from clinical malaria [12-14].
In this study, we have chosen an approach based on the display of promising Plasmodium falciparum derived malaria antigens upon surface of the RNA coliphage $\mathrm{Q} \beta$ for effective presentation to the immune system. The Merozoite surface protein 3 (MSP3) and UB05 are two malaria parasite blood-stage antigens validated as potential malaria vaccine candidates following analysis of their role in protective immunity in children and adults [14-17].

In order to circumvent the predominant antigen variability of the $\mathrm{N}$-terminal of $48-\mathrm{kDa}$ MSP3 protein we targeted just the conserved Cterminal aa of MSP-3 which has been demonstrated [16,18] to contribute to semi-immunity to blood stage malaria in both children and adult.

Immune responses targeting the conserved C-terminal 88 aa of MSP-3 for example have been directly implicated in long term protection [19] and strong reduction in incidence of clinical malaria [20]. This is mainly because this region is not only conserved across different parasite strains [21-23]; but equally possessed epitopes confirmed to be targeted by antibodies associated with protection $[18,23]$. Similarly UB05 antigen specific immune responses have been reported as a potential marker of protective immunity against malaria $[14,24,25]$.

In this study we genetically engineered the malaria blood stage immunogens UB05, MSP3 and their chimera UB05-MSP3 upon the surface of the RNA coliphage $\beta$, then used the ensuing recombinant phages to assess semi immunity to malaria in children in a high malaria transmission region of Cameroon. Recombinant chimera $\beta \mathrm{UB} 05-\mathrm{MSP} 3$ becomes necessary since malaria vaccines containing more than one fusion antigen have been demonstrated to induce effective immunity [24] resulting to protection against clinical malaria in African children [26-28]. Since anti-UB05 and anti-MSP3 antibodies have each been incriminated with protection against malaria this new antigen combinations might more reliably detect antibody responses which are predictive of protective ability of the immune system from clinical malaria.

\section{Materials and Methods}

Media used for bacteria culture and phages were purchased from Fisher Scientific (Pittsburgh, PA). Restriction enzymes and T4 ligase were purchased from New England BioLabs (Ipswich, $\mathrm{MA}$ ). $\mathrm{RbCl}$ and $\mathrm{CaCl}_{2}$ including other major reagents were purchased from SigmaAldrich (St. Louis, MO). DNA preparation for clones screening and PCR clean up kit was purchased from QIAGEN (Valencia, CA). IgG Mouse monoclonal antibodies specific to $\mathrm{C}$ and N-terminal of UB05 and MSP3 proteins were purchased from Abmart (Xietu Road, Shanghai). Horseradish peroxidase (HRP)-conjugated, mouse anti- 
Citation: Waffo AB, Lissom A, Ouambo HF, Ngu LN, Ngoh AA, et al. (2018) Surface Engineering of the RNA Coliphage Q $\beta$ to Display Plasmodium Falciparum Derived Asexual Blood Stage Antigens UB05 and Merozoite Surface Protein 3. Clin Microbiol 7: 314 . doi: $10.4172 / 2327-5073.1000314$

Page 3 of 10

human IgG, IgG1, IgG3 and gG4 antibodies were purchased from Southern Biotech (Birmingham, USA).

\section{Microorganisms}

E. coli MC1016 (Invitrogen, Grand Island, NY) was used to grow and maintain the plasmids. E. coli $\mathrm{HB} 101$ was used to grow and maintain $\mathrm{pQ} \beta 8 \Delta \mathrm{A}$ land their recombinant products. E. coli ATCC 23725 (K12) was used for phage production and titration. A control plasmid, $\mathrm{pQ} \beta \Delta \mathrm{A} 1$, was also maintained and amplified with the same cell.

\section{Design and 3D structural modelling of the recombinant Q $\beta M S P 3, Q \beta U B 05$ and Q $\beta U B 05-M S P 3$ phages}

Amino acid sequences for codon optimized MSP3, UB05 and chimeric UB05-MSP3 immunogens were cloned in expression cassettes as indicated in Figure 1. The expression cassettes were analysed using the sequence analysis software DNA strider while taking into consideration the secondary structure of the RNA of the recombinant coliphage as previously reported $[18,23]$. The designed MSP3, UBO5 and UBO5MSP3 regions included an SSGGG linker flanked with the restriction site Not1 for cloning. The first PCR was done by annealing and extending with primers UBO5-NotIF and UB05-NotIR to obtain the UB05 insert. The MSP3 insert was amplified with the primers MSP3-NotIF and MSP3-NotIR and similarly treated. Using partially complementary primer designs, the products of the first two PCR were used as a template in an overlap PCR to generate the chimeric UB05-MSP3 inserts. Restriction enzyme site is bold and underlined (Table 1). All primers were designed to maintain the reading frame and important secondary structure of hybrid phage RNA. The sequences for the minor coat protein A1 and engineered proteins were modelled using the template based modelling using Raptor X web server (doi: 10.1038/nprot.2012.085). The models were then transformed to view the protein backbone and highlight the secondary structures using MolGro molecular viewer. The structures were next aligned to understand the differences among the protein models.

UB05-NotIF:

5' ttatGCGGCCGCAtgggcagccagattcagccgagccgctttctggatagcgcgatt

UB05-NotIR:

5' ggtggcggccgcTTACTAttttttttatcgcggttcaggcggttcgg

MSP3-NotIF:

5'ccacGCGGCCGCCgcaaaaccaaagaatatgcggaaaaagcgaaaaacgcgtatgaaaaagc

MSP3-NotIR:

5' ccaatagcggccgcTTACTAttccagttcttcttcttcggtttcttccgcttcttcttcttttcatcc

Table 1: List of primers used to amplify the UB05 and MSP3 regions.

\section{Cloning and production of recombinant MSP3, UB05 and UB05MSP3 phages}

The cloning vector $\mathrm{pQ} \beta 8 \Delta \mathrm{A} 1$ and the inserts including MSP3, UB05 and UB05-MSP3 were prepared and the recombinant plasmids generated as previously reported in our group [29]. Confirmed plasmids were sequenced to validate fusion and ensure that the inserts were in frame at the end of the minor coat protein A1. Validated positive clones were used to retransform E. coli HB 101 for phage production.

\section{Phage production and characterization}

Validated clones were selected and inoculated into the nutrient media (2YT), and allowed to grow at $37^{\circ} \mathrm{C}$ for $4 \mathrm{hrs}$ while shaking $(150$ $\mathrm{rpm}$ ). Each culture was then scaled up to one litre of $2 \mathrm{YT}$ and allowed to grow at $37^{\circ} \mathrm{C}$ for $18 \mathrm{hrs}$ while shaking $(150 \mathrm{rpm})$. The resultant recombinant phage was precipitated using $29 \mathrm{~g}$ of $\mathrm{NaCl}$ and $80 \mathrm{~g}$ of polyethyleneglycol (PEG8000) and amplified using the indicator E. coli strain K12. One percent of the fresh overnight culture of $\mathrm{K} 12$ on nutrient media (TGY) was amplified at $37^{\circ} \mathrm{C}$ while shaking (180 rpm) for 3-5 hrs to reach an OD 600 of 0.6-0.8. Each recombinant phage was inoculated to the culture at a multiplicity of two and incubated at $37^{\circ} \mathrm{C}$ for $18 \mathrm{hrs}$ on a racking platform $(150 \mathrm{rpm})$. The recombinant phage were produced and characterized as previously described in our group [29].

\section{Western blot analysis of recombinant Q $\beta$ MSP3, Q $\beta$ UB05 and $Q \beta U B 05-M S P 3$ phages for the expression of their respective proteins}

About $92.5 \mu \mathrm{l}$ of each recombinant phage was mixed with $2.5 \mu \mathrm{l}$ of $\beta$-Mercaptoethanol and $5 \mu \mathrm{l}$ SDS (20\%) then incubated for $1 \mathrm{hr}$ at $37^{\circ} \mathrm{C}$. Then $100 \mu \mathrm{l}$ of $2 \mathrm{x}$ Laemmli SDS buffer was added and further incubated for 10 mins at $100^{\circ} \mathrm{C}$. The samples were loaded in a $10 \%$ polyacrylamide gel and allowed to run for $1 \mathrm{hr}$ intervals at 30,50 and 70 volts. The separated proteins were then transferred unto a nitrocellulose membrane, blocked with $1 \mathrm{x}$ roti block and probed with Plasma containing high titers of MSP3 and UB05 specific polyclonal antibodies. Specific recognition of the immunogens was revealed with Horse radish peroxidase-conjugated Mouse anti-human IgG (Southern Biotech, Birmingham, USA) diluted 1:4000 in 1x roti block. Bound conjugate was detected using 1-step ultra TMB blotting solution (Thermoscientific, USA) and the HRP reaction stopped by washing with molecular grade pure water.

\section{Reactivity of the recombinant phages Q $\beta$ UB05, Q $\beta$ MSP3 and Q $\beta U B 05 M S P 3$ with monoclonal antibodies targeting the $N$ - and C-terminal regions of UB05 and MSP3 antigens}

The recombinant phages including Q $\beta \mathrm{UB} 05, \mathrm{Q} \beta \mathrm{MSP} 3$ and Q $\beta$ UB05-MSP3 were diluted seperately in PBS so that $100 \mu \mathrm{l}$ containing 107 phage particles were added/well to high binding 96well flat bottom microsorp (Thermo Fisher Scientific) ELISA plates and incubated overnight at $4{ }^{\circ} \mathrm{C}$. The following day, plates were washed $3 \mathrm{x}$ with PBST (PBS with $0.05 \%$ Tween-20) and blocked either with $3 \%$ BSA or 1x Roti block (Carl ROTH, Karlsruhe, Germany) for one hour at $37^{\circ} \mathrm{C}$. The coated plates were then probed with graded doses of monoclonal antibodies X-Q38G73-N (anti-UB05 N-terminal), XQ38G73-C (anti-UB05 C-terminal), X-Q0KGH2-M (anti-MSP3 Mterminal) and X-Q0KGH2-C (anti-MSP3 C-terminal) diluted in $2 \%$ BSA at the concentrations $1000,100,10,1$ and $0.1 \mathrm{ng} / \mathrm{ml} .100 \mu \mathrm{l}$ of the diluted antibodies was added per well and incubated for two hours at $37^{\circ} \mathrm{C}$. Unbound antibodies were removed by washing $5 \mathrm{x}(198 \mu \mathrm{l} /$ well $)$ with PBST. Reactivity of the monoclonal antibodies with the recombinant phages were probed with Horse radish peroxidaseconjugated Goat anti-mouse IgG (Southern Biotech, Birmingham, USA) diluted at 1:4000 in 0.1x Roti block. Bound conjugate was detected using ABTS substrate and the HRP reaction stopped by 
Citation: Waffo AB, Lissom A, Ouambo HF, Ngu LN, Ngoh AA, et al. (2018) Surface Engineering of the RNA Coliphage Q $\beta$ to Display Plasmodium Falciparum Derived Asexual Blood Stage Antigens UB05 and Merozoite Surface Protein 3. Clin Microbiol 7: 314 . doi: $10.4172 / 2327-5073.1000314$

Page 4 of 10

adding $100 \mu \mathrm{l}$ a stop solution according to the manufacturer's protocol (Southern Biotech, Birmingham, USA). The colorimetric signal was measured at $405 \mathrm{~nm}$ using a multiscan FC microplate reader (Thermo Fisher Scientific, USA).

\section{Study site and population}

The study was conducted in Bikop, a rural community $48 \mathrm{~km}$ away from Yaounde the capital city of Cameroon. This is a region with intense perennial malaria driven by a dominant $P$. falciparum infection. A total of 348 children aged between 2 to 15 years both positive and negative for malaria by rapid diagnostic test (SD Bioline Malaria Ag p.f./pan, Ingbert Germany) and microscopy were recruited for this study.

\section{Plasma sample collection and processing}

Samples were collected from consented participants from November 2014 to November 2017. Blood samples were collected into $4 \mathrm{ml}$ plastic Vacuum blood spray-coated K2EDTA tubes called Vacutest (Vacutestkirma, Italy). All samples were stored at room temperature and processed within $4 \mathrm{hrs}$ of collection. To obtain plasma, samples were centrifuged at $2,000 \mathrm{rpm}$ for $10 \mathrm{~min}$ at $4^{\circ} \mathrm{C}$. The plasma fraction was harvested sterile under a biosafety hood, aliquoted in small, singleuse volumes and stored at $-20^{\circ} \mathrm{C}$ until use. The plasma obtained from participants was heat inactivated for 30 minutes at $56^{\circ} \mathrm{C}$ prior to ELISA assay.

\section{Reactivity of the recombinant phages Q $\beta$ UB05, Q $\beta M S P 3$ and QßUB05-MSP3 with plasma from children}

The plasma levels of antibodies specific to the malaria immunogens UB05, MSP3 and UB05-MSP3 were determined by ELISA assay. Briefly high binding ELISA plates were coated with $10^{7}$ particles/well of each recombinant phage and incubated overnight at $4^{\circ} \mathrm{C}$ as described above. The following day, Plates were washed $3 \mathrm{x}$ with PBST (PBS containing 0.05\% Tween 20) and blocked with 3\% Bovine serum albumin (BSA) in PBST for one hour at $37^{\circ} \mathrm{C}$. Heat inactivated plasma from both malaria positive and negative children were diluted serially in PBS then $100 \mu \mathrm{l} /$ well added in triplicate and incubated for two hours at $37^{\circ} \mathrm{C}$. The plates were washed $5 \mathrm{x}(198 \mu \mathrm{l} /$ well $)$ with PBST after which the bound antibodies were probed with the peroxidase-conjugated mouse anti-human IgG (Southern Biotech, Birmingham, USA) diluted 1:2000 in PBS. Bound conjugate was detected using ABTS substrate and stop solution according to the manufacturer's protocol (southern biotech, Birmingham USA). The colorimetric signal was measured at $405 \mathrm{~nm}$ using a multiscan FC microplate reader (Thermo Fisher Scientific, USA). ELISA titre was expressed as arbitrary units (AU) based on five human samples with high anti-UBO5-MSP3 specific IgG antibodies.

\section{Statistical analysis}

Data analysis was performed with Graphpad Prism Software version 6.1. First a one way ANOVA was used to assess if there were differences between the means. The Tukey multiple comparison test and kruskal-Wallis were then used to determine which of the means were different. Statistical significance was confirmed when $\mathrm{P}<0.05$.

\section{Results}

\section{Design and generation of $p Q \beta U B 05, p Q \beta M S P 3$ and pQ $\beta$ UB05-MSP3 plasmid vector variants}

We previously demonstrated that up to $300 \mathrm{bp}$ of foreign sequences could be inserted into the minor coat protein gene A1 of $Q \beta$ phage, without affecting its functionality [29-31]. Similarly the plasmids $\mathrm{pQ} \beta \triangle \mathrm{A} 1$ was used to generate expression cassettes for UB05

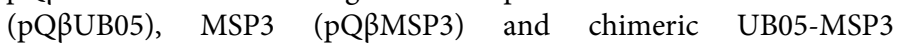
(pQBUB05-MSP3) (Figure 1C to 1E). The sequences of codon optimized UB05 (Genbank accession Number DQ235690) and 96 amino acids (146-243) derived from the conserved C-terminal region of $P$. falciparum MSP3 (Genbank accession number AMM75921.1) were amplified from a previously generated codon optimized construct and clone in the expression cassette (Figure 1A). UB05 and MSP3 regions were amplified with the primers indicated in Table 1 to contain the Not1 restriction sites indicated in bold for subsequent cloning. In S1a data is shown for the PCR amplification of the different antigens alongside the cloning vectors. The secondary structure of all recombinant phage RNA was analysed to ensure that all major features necessary for recombinant phage expression were conserved.

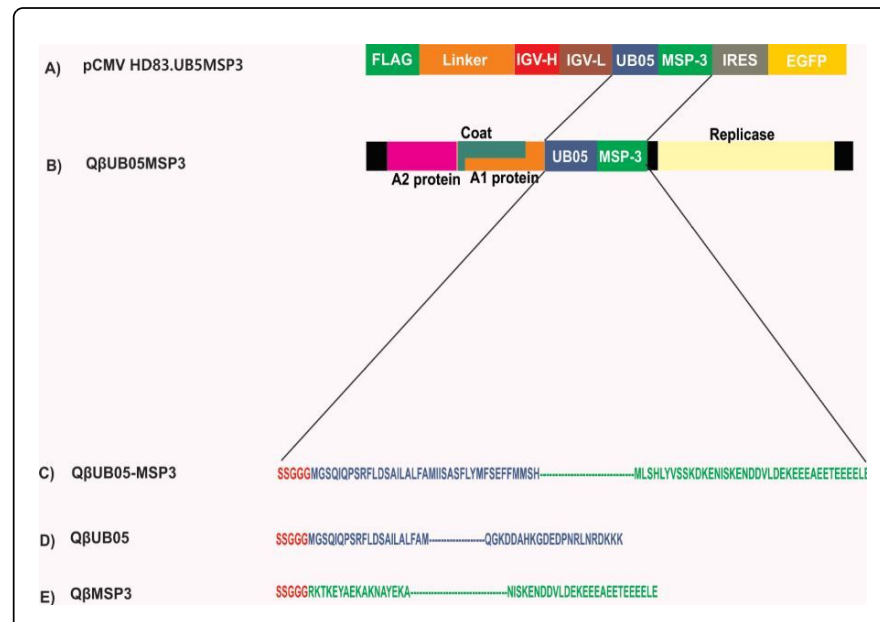

Figure 1: Schema of the recombinant Q $\beta M S P 3, Q \beta U B 05$ and Q $\beta$ UB05-MSP3 sequences. In (A) schema of pCMV HD83.UBO5MSP3 plasmid map from where UB05 and MSP3 antigens were amplified using PCR. In (B) schema of $\mathrm{Q} \beta$ indicating the deletion in the $\mathrm{C}$-terminal end of the minor coat protein $\mathrm{A} 1$ where the chimeric UB05-MSP3 region inserted. In (C) amino acid sequence of the recombinant phage Q $\beta$ UB05-MSP3. In (D) and (E) amino acid sequences of the recombinant phages Q $\beta \mathrm{UBO} 5$ and $\mathrm{Q} \beta \mathrm{MSP} 3$ respectively.

\section{D modelling to determine the localization of the inserted UB05 and MSP 3 regions within the minor coat protein A1}

Next using knowledge of the confirm three dimensional structures of mutant A1 protein fused with various peptides as previously demonstrated in our consortium [29,31] we conducted a comparative three dimensional modelling of the three newly fused proteins including UB05, MSP3 and UB05-MSP3. In this regards their respective amino acid sequences were used together with minor coat protein $\mathrm{A} 1$ of the coliphage $\mathrm{Q} \beta$ for a three-dimensional (3D) modelling 
Citation: Waffo AB, Lissom A, Ouambo HF, Ngu LN, Ngoh AA, et al. (2018) Surface Engineering of the RNA Coliphage Q $\beta$ to Display Plasmodium Falciparum Derived Asexual Blood Stage Antigens UB05 and Merozoite Surface Protein 3. Clin Microbiol 7: 314 . doi: $10.4172 / 2327-5073.1000314$

Page 5 of 10

as previously reported in our group [29]. The resultant derivatives including the wild type, Q $\beta$ MSP3, Q $\beta \mathrm{UB} 05$ and $\mathrm{Q} \beta \mathrm{UB} 05-\mathrm{MSP} 3$ respectively are shown in Figure 2. The 3D structural modelling revealed that the UB05, MSP3 and UB05-MSP3 regions were displayed respectively in the $\mathrm{C}$-terminal end of the minor coat protein $\mathrm{A} 1$ as indicated by corresponding changes in their conformation when compared to the wild type minor coat protein A1. This was in contrast to the $\mathrm{N}$ terminus of the minor coat protein $\mathrm{A} 1$ protein, which apparently was not significantly changed conserving its $\alpha$-helixes and $\beta$-sheets structurally in all models. With respect to structural homology with wild type Al protein the modification in the C-terminal of the modified minor coat protein.

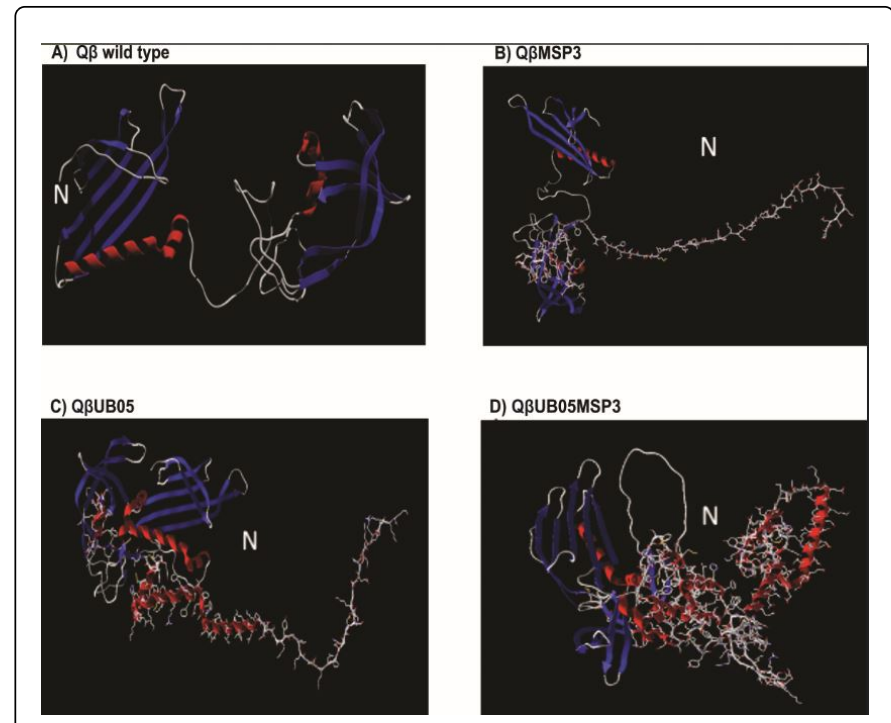

Figure 2: Three-dimensional structures predicted for the wild type and engineered $\mathrm{Q} \beta$ minor coat protein A1. (A) $\mathrm{Q} \beta$ wild type. (B) Q $\beta M S P 3$. (C) Q $\beta$ UB05. (D) Q $\beta$ UB05-MSP3. UB05 and MSP3 highlighted in ball and stick rendering at the $\mathrm{C}$ terminal region of the protein. $\mathrm{N}$ indicates the $\mathrm{N}$ terminus of the minor coat protein $\mathrm{A} 1$; red and blue coloured structures indicate $\alpha$-helix and $\beta$-sheets, respectively.

A1 seemed to have impacted upon the rotation of its $\mathrm{N}$-terminus (Figure 2B to 2D). Never the less the UB05, MSP3 and UB05-MSP3 proteins were confirmed to be exposed at the $\mathrm{C}$-terminus around the $\beta$-sheets and between the N-terminal domains. Further comparative structural modelling of the $\mathrm{C}$-terminus of the recombinant minor coat protein A1; situated it to the outer surface of the capsid as shown in the ball and stick depiction (Figure 2B to 2D). This was similar to previous three-dimensional models of A1 fused proteins reported in our group which had been demonstrated to efficiently display surface accessible peptides [29,31].

\section{Recombinant Phage production strategy and genetic characterization}

Due to the fact that an insertion of a foreign antigen upon the surface of $\mathrm{Q} \beta$ generally results to a significant reduction in recombinant phages titres we adopted methods previously optimized by our group to ensure adequate phage yield [29]. Briefly the recombinant phages obtained after the first round of amplification in one litre of culture medium, were precipitated and suspended in $10 \mathrm{ml}$ of media followed by 3 more rounds of amplification each with an inoculating multiplicity of infection (MOI) of 3. To improve recombinant phage yield, $E$ coli $\mathrm{Q} 13$ the natural host of the phage Q $\beta$ was used instead of E. coli HB101 as previously reported [29]. This resulted into a significant increase $(\mathrm{P}<0.0001)$ in the yield of the resultant recombinant phages $\left(10^{14} \mathrm{pfu} / \mathrm{ml}\right.$ compared to $\left.10^{8} \mathrm{pfu} / \mathrm{ml}\right)$ which were then used for subsequent analysis. An analytical gel electrophoresis for the selection of recombinant Q $\beta$ UB05-MSP3 phage is shown in S1b. The recombinant phages were characterized as reported previously [29]. Thus, the insertion of the MSP3, UB05 and UB05MSP3 regions into the minor coat protein A1 of the coliphage Q $\beta$ permits efficient surface display of the MSP3, UB05 and UB05-MSP3 antigens without affecting viability and infectivity.

\begin{tabular}{|c|c|}
\hline Antibodies & Epitopes \\
\hline \multirow{3}{*}{$\begin{array}{l}\text { X-QOKGH2-M } \\
\text { (MSP3 M-terminal) }\end{array}$} & AKDDAEKSSKAD \\
\hline & KADSISTKTKEY \\
\hline & KDKENISKENDD \\
\hline \multirow{3}{*}{$\begin{array}{l}\text { X-QOKGH2-C } \\
\text { (MSP3 C-terminal) }\end{array}$} & DVLDEKEEEAEETE \\
\hline & EISEDEEEEEEEEE \\
\hline & QSNENNDQKKDMEA \\
\hline \multirow{3}{*}{$\begin{array}{l}\text { X-Q38G73-N } \\
\text { (UB05 N-terminal) }\end{array}$} & MGSQIQPSRFLDSA \\
\hline & MMSHESKLFNNKLS \\
\hline & RLFPFKTFEYNLTH \\
\hline \multirow{3}{*}{$\begin{array}{l}\text { X-Q38G73-C } \\
\text { (UB05 C-terminal) }\end{array}$} & LSLKPDSVSSKYGL \\
\hline & KDSRKPQGKDDAHK \\
\hline & GDEDPNRLNRDKKK \\
\hline
\end{tabular}

Table 2: Monoclonal antibodies and their respective epitopes.

\section{Reactivity of the recombinant phages Q $\beta M S P 3, Q \beta U B 05$ and $Q \beta U B 05-M S P 3$ with monoclonal antibodies targeting the $\mathrm{N}$-, $\mathrm{M}$ - and C- terminal regions of the inserted proteins}

The recombinant phages $\mathrm{Q} \beta \mathrm{UB} 05, \mathrm{Q} \beta \mathrm{MSP} 3$ and $\mathrm{Q} \beta \mathrm{UB} 05-\mathrm{MSP} 3$ were assessed for reactivity with monoclonal antibodies recognizing the N-, M- and C-terminal regions of either UB05 or MSP3 (Table 2). Briefly ELISA plates were coated with $10^{7} \mathrm{pfu} /$ well of Q $\beta M S P 3$, Q $\beta$ UB05 and Q $\beta$ UB05-MSP3 respectively as described in materials and methods then probed with graded doses of each monoclonal antibody. As shown in figure $3 \mathrm{~A}$ the recombinant phage Q $\beta \mathrm{UB} 05$ reacted specifically with the monoclonal antibodies X-Q38G73-N (anti-UB05 N-terminal) and X-Q38G73-C (anti-UB05 C-terminal) while in figure $3 \mathrm{~B}$ recombinant phage $\mathrm{Q} \beta \mathrm{MSP} 3$ reacted exclusively only with monoclonal antibodies X-Q0KGH2-M (anti-MSP3 Mterminal sequences in the middle) and X-Q0KGH2-C (anti-MSP-3 Cterminal) in a dose dependent manner. Similarly the recombinant phage Q 3 UB05-MSP3 (Figure 3C) displaying the chimeric UB05MSP3 antigen reacted with all four monoclonal antibodies in a dose dependent manner clearly indicating that both immunogens were built upon the surface of the recombinant phage. Comparative to the antiC-terminal portion targeting monoclonal antibodies, the N-terminal region of each insert reacted more strongly with their corresponding antibodies for all three recombinant phages. The specific recognition of 
Citation: Waffo AB, Lissom A, Ouambo HF, Ngu LN, Ngoh AA, et al. (2018) Surface Engineering of the RNA Coliphage Q $\beta$ to Display Plasmodium Falciparum Derived Asexual Blood Stage Antigens UB05 and Merozoite Surface Protein 3. Clin Microbiol 7: 314 . doi: $10.4172 / 2327-5073.1000314$

Page 6 of 10

all three recombinant phages by malaria antigen specific antibodies was further confirmed in western blot analysis (Figure 3D).

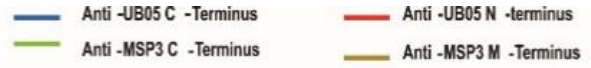

A) Coated with QßBMSP3
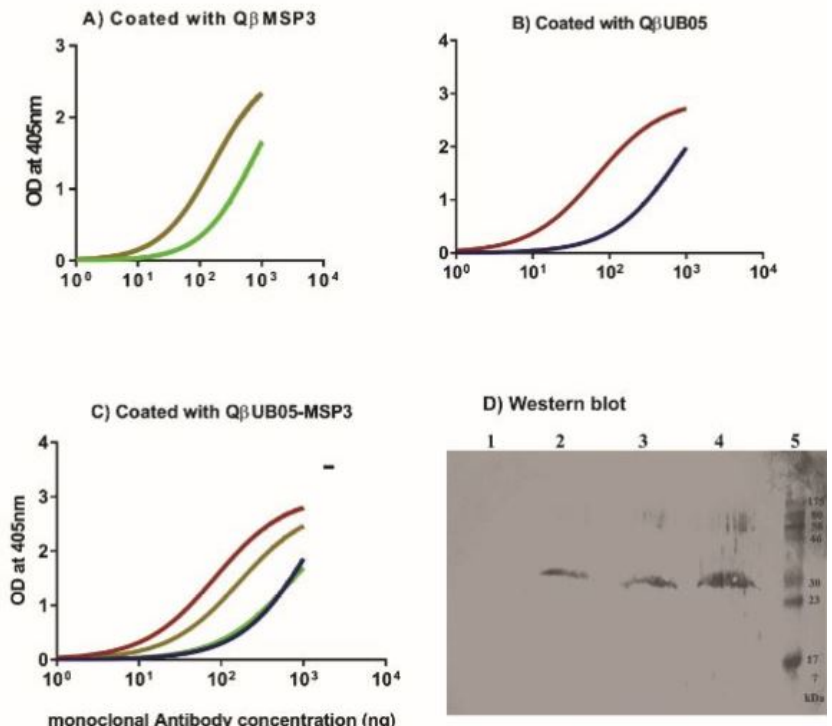

Figure 3: Western blot analysis and antigenicity of the recombinant Q $\beta$ MSP3, Q $\beta$ UB05 and Q $\beta$ UB05-MSP3 phages with monoclonal antibodies targeting the $\mathrm{N}$ and $\mathrm{C}$-terminals of the inserts. In (A) (B) \& (C) binding of recombinant Q $\beta M S P 3, Q \beta U B 05$ and Q $\beta U B 05-$ MSP3 phages with $\mathrm{N}$ and $\mathrm{C}$-terminal targeting monoclonal antibodies. Anti-UB05 N-terminal (brown line), anti-UB05 Cterminal (black line), anti-MSP3 M-terminal (red line) and antiMSP3 C-terminal (blue line). In (A) reactivity of graded concentrations of anti-UB05 N-terminal (X-Q38G73-N) and antiUB05 C-terminal (X-Q38G73-C) monoclonal antibodies with the recombinant $\mathrm{Q} \beta \mathrm{UB} 05$ phage. In (B) reactivity of graded doses of anti-MSP3 M-terminal (X-Q0KGH2-M) and anti-MSP3 C-terminal (X-Q0KGH2-C) monoclonal antibodies with recombinant Q $\beta M S P 3$ phage. In $(\mathrm{C})$ reactivity of graded doses of all four monoclonal antibodies with recombinant Q $\beta$ UB05-MSP3 phage. In (D) data is shown for the western blot analysis of the recombinant phages. Lane 1 is a Mock (Q $\beta$ MPER), lane 2 is recombinant $Q \beta$ UB05-MSP3, lane 3 is recombinant $\mathrm{Q} \beta \mathrm{UB} 05$, lane 4 is recombinant $\mathrm{Q} \beta \mathrm{MSP} 3$ and lane 5 is the protein marker.

\section{Study population characteristics}

A total of 348 children were enrolled after written informed consent as described in materials and methods. The children were from a perennial high malaria transmission region of Cameroon $48 \mathrm{~km}$ away from the capital City. This implies that the children were exposed to the same rate of mosquito bite during their life. The age range of participants was between 2 to 15 years old. Amongst the children enrolled 224 were diagnosed malaria positive with Plasmodium falciparum accounting for $82 \%$ of cases and the rest being a mixture with other malaria parasite strains ( $P$. falciparum mixed with either $P$. ovale or $P$. malariae). Both malaria positive and negative children were stratified into three age categories consisting of two to four years $(<5)$, six to ten years and eleven to fifteen years (Table 3 ).

\begin{tabular}{|c|c|c|}
\hline & $\begin{array}{l}\text { Malaria positive } \\
(\mathrm{n}=224)\end{array}$ & $\begin{array}{l}\text { Malaria negative } \\
(n=124)\end{array}$ \\
\hline \multicolumn{3}{|c|}{ Gender $n(\%)$} \\
\hline Male & $129(58)$ & $62(50)$ \\
\hline Female & $95(42)$ & $62(50)$ \\
\hline \multicolumn{3}{|l|}{ Age $n(I Q R)$} \\
\hline$<5$ years & $67(2-5)$ & $43(3-5)$ \\
\hline $6-10$ years & $117(6-10)$ & $55(6-10)$ \\
\hline$>10$ years & $40(11-15)$ & $26(11-13)$ \\
\hline \multicolumn{3}{|c|}{ Temperature ${ }^{\circ} \mathrm{C}$ mean (IQR) } \\
\hline$<5$ years & $36.32(36-37)$ & $36.54(36-38)$ \\
\hline $6-10$ years & $36.41(36-37)$ & $36.13(35-37)$ \\
\hline$>10$ years & $36.14(35-37)$ & $36(35-37)$ \\
\hline \multicolumn{3}{|c|}{ LLIN $=$ Yes n $(\%)$} \\
\hline$<5$ years & $39(58)$ & $30(70)$ \\
\hline $6-10$ years & $67(57)$ & $39(71$ \\
\hline$>10$ years & $23(40)$ & $17(65)$ \\
\hline \multicolumn{3}{|c|}{ Haemoglobin g/dL mean (IQR) } \\
\hline$<5$ years & $9.2(4.7-15.8)$ & $12.44(4.20-15.80)$ \\
\hline $6-10$ years & $10.35(6.6-15.2)$ & $11.38(6.9-13.20)$ \\
\hline$>10$ years & $11.73(9.8-14.9)$ & $12.52(10.5-15.1)$ \\
\hline
\end{tabular}

Table 3: Study population characteristics.

\section{Comparative analysis of the antigenicity of the recombinant phages Q $\beta$ UB05, Q $\beta$ MSP3 and Q $\beta$ UB05-MSP3 for reactivity with polyclonal antibodies in plasma from malaria negative children}

Since antibodies specific to multiple $P$. falciparum antigens have been associated with semi immunity in children [32] we compared the three recombinant phages including $\mathrm{Q} \beta \mathrm{UB} 05, \mathrm{Q} \beta \mathrm{MSP} 3$ and their chimera Q $\beta$ UB05-MSP3 with respect to reactivity with polyclonal antibodies in plasma from malaria negative children. In figure 4 whereas all three recombinant phages reacted strongly with polyclonal plasma in all the three age groups, children older than ten years showed the highest plasma levels of antigen specific IgG antibodies. In contrast children less than five years showed the least plasma levels of antigen specific IgG antibodies (compare Figure 4A, 4B and 4C) which were significantly less $(\mathrm{P}<0.0001)$ when compared to values in plasma from children greater than 10 years old group. IgG antibody level of children five to ten years old was superior to levels in children less than 5 years old. However these antibody levels were significantly higher only for the recombinant phage Q $\beta$ UB05-MSP3 $(\mathrm{P}<0.0045)$. 
Citation: Waffo AB, Lissom A, Ouambo HF, Ngu LN, Ngoh AA, et al. (2018) Surface Engineering of the RNA Coliphage Q $\beta$ to Display Plasmodium Falciparum Derived Asexual Blood Stage Antigens UB05 and Merozoite Surface Protein 3. Clin Microbiol 7: 314 . doi: $10.4172 / 2327-5073.1000314$

Page 7 of 10
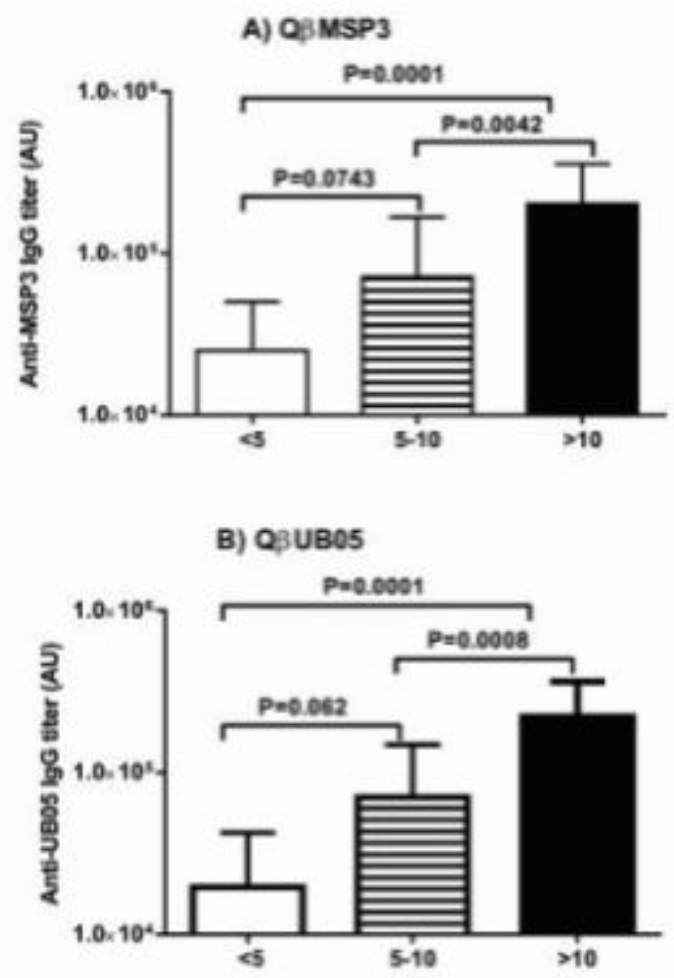

C) QSUBO5-MSP3

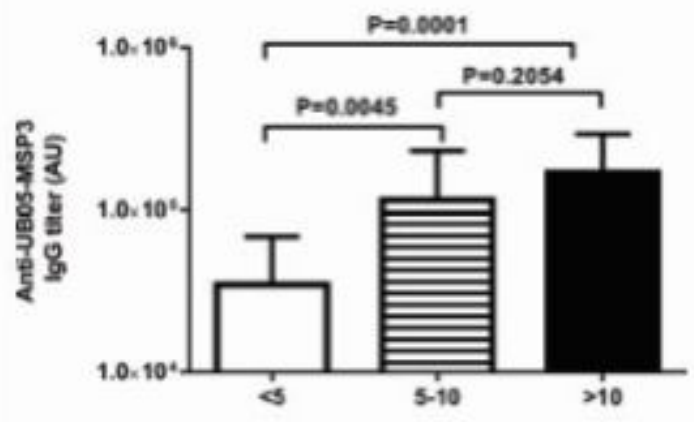

Age groups

Figure 4: Antigenicity of the recombinant phages Q $\beta M S P 3$, $\mathrm{Q} \beta \mathrm{UB} 05$ and $\mathrm{Q} \beta \mathrm{UB} 05-\mathrm{MSP} 3$ in plasma from malaria negative children. Plasma of malaria negative participants was tested for reactivity with the different recombinant phages including $\mathrm{Q} \beta \mathrm{MSP} 3, \mathrm{Q} \beta \mathrm{UB} 05$ and $\mathrm{Q} \beta \mathrm{UB} 05 \mathrm{MSP} 3$. In (A) data is shown for the reactivity of the recombinant phage $\mathrm{Q} \beta \mathrm{MSP} 3$ with plasma from participants of different age groups. In (B) and (C) same as in (A) but here the antigens used were the recombinant phages QBUB05 and Q $\beta$ UB05-MSP3 respectively. Here, plasma from children older than 10 years was significantly more reactive with the recombinant phages $(\mathrm{P}<0.0001)$ than in the other age groups.

Similarly antigen specific antibody levels in children greater than 10 years old were significantly higher than values in the 5-10 age groups for both Q $\beta \mathrm{UB} 05$ and Q $\beta$ MSP3. On the other hand reactivity with Q $\beta$ UB05-MSP3 was not significantly different between the 5-10 and the greater than 10 years old age groups. Overall, the antigenicity of the phage displayed malaria parasite derived antigens was dependent upon the age of the participants increasing correspondingly with age. However the recombinant phage Q $\beta$ UB05-MSP3 proved superior in distinguishing the participants into those who have significantly high antibody levels (children older than five years) and those with less antibody levels (children less than five years old). Thus the recombinant phage Q $\beta$ UB05-MSP3 could be used to track antibody responses in malaria negative children.

\section{Reactivity of the recombinant phages $\mathrm{Q} \beta \mathrm{UB} 05, \mathrm{Q} \beta \mathrm{MSP} 3$ and Q $\beta$ UB05-MSP3 with polyclonal antibodies in plasma from malaria positive children}

Similarly we also compared the reactivity of the three recombinant phages $\mathrm{Q} \beta \mathrm{UB} 05$, Q $\beta$ MSP3 and $\mathrm{Q} \beta \mathrm{UB} 05-\mathrm{MSP} 3$ with polyclonal antibodies in plasma from malaria positive children. During acute malaria individuals older than five years showed comparatively higher antibody levels. However with respect to children 5-10 years old the antibody levels were not significantly higher for all the recombinant phages including $\mathrm{Q} \beta \mathrm{UB} 05 \quad(\mathrm{P}<0.08), \mathrm{Q} \beta \mathrm{MSP} 3 \quad(\mathrm{P}<0.0082)$ and $\mathrm{Q} \beta$ UB05-MSP3 $(\mathrm{P}<0.063)$ respectively. As shown in figure $5 \mathrm{~A}$ to $5 \mathrm{C}$ in children older than 10 years significantly higher antibody levels were observed for Q $\beta$ MSP3 $(\mathrm{P}<0.0041)$, Q $\beta \mathrm{UB} 05(\mathrm{P}<0.0120)$ and $\mathrm{Q} \beta \mathrm{UB} 05$ MSP3 $(\mathrm{P}<0.0021)$ respectively. However between the groups of children 5-10 and greater than 10 years old, no difference is observed in the antibody levels for all the recombinant phages including Q $\beta$ UB05 $\quad(\mathrm{P}<0.4518) \quad \mathrm{Q} \beta \mathrm{MSP} 3 \quad(\mathrm{P}<0.6204)$ and $\mathrm{Q} \beta \mathrm{UB} 05-\mathrm{MSP} 3$ $(\mathrm{P}<0.4412)$. Thus during acute malaria all recombinant phages were able to detect antigen specific antibodies in all the age group with the age of the participants being the deciding factor.

\section{Discussion}

In this study we have engineered Plasmodium falciparum derived UB05, MSP3 and also a chimera of the two antigens; UB05-MSP3 upon the surface of the RNA coliphage $Q \beta$. Surface engineering of $Q \beta$ allowed us to display as a single unit UB05 and MSP3 upon the surface of the recombinant phage as a bivalent malaria vaccine candidate. All immunogens were built upon the recombinant $\mathrm{Q} \beta$ phage by genetically inserting their corresponding sequences into an optimized C-terminal part of its A1 protein as previously described by our group. Genetically linking of promising immunogens to the surface of $\mathrm{Q} \beta$ virus like particles allows them to be displayed at high density $[29,31,33]$. This high-density display, as previously reported in our group in turn can dramatically enhance antigenicity and immunogenicity of the desired immunogen [29]. This organized display of antigen upon the surface of recombinant $\mathrm{Q} \beta$ phage particle has also been demonstrated by [34] in the context of tumor vaccine development. To boost the immunogenicity of malaria vaccines $\mathrm{Q} \beta$ virus like particles has also previously been chemically conjugated to CSP [35] or Pfs25 [36].

Once displayed upon the recombinant phage the chimeric $\mathrm{Q} \beta \mathrm{UB} 05-$ MSP3 must maintain its native form to ensure that immunologically relevant epitopes are available for immune recognition. Therefore in three dimensional modelling and transmission electron microscopy (data not shown) we could confirm that the immunogens were exposed upon the surface of all the recombinant phages. In ELISA assay using defined epitopes targeting monoclonal antibodies we demonstrated that all recombinant phages were strongly recognized by their respective $\mathrm{N}$-, $\mathrm{M}$ - and C-terminal specific monoclonal antibodies. 
Citation: Waffo AB, Lissom A, Ouambo HF, Ngu LN, Ngoh AA, et al. (2018) Surface Engineering of the RNA Coliphage Q $\beta$ to Display Plasmodium Falciparum Derived Asexual Blood Stage Antigens UB05 and Merozoite Surface Protein 3. Clin Microbiol 7: 314 . doi: $10.4172 / 2327-5073.1000314$

Page 8 of 10

Our consortium has previously optimized strategies to enhance the yield of recombinant $\mathrm{Q} \beta$ phages [29].

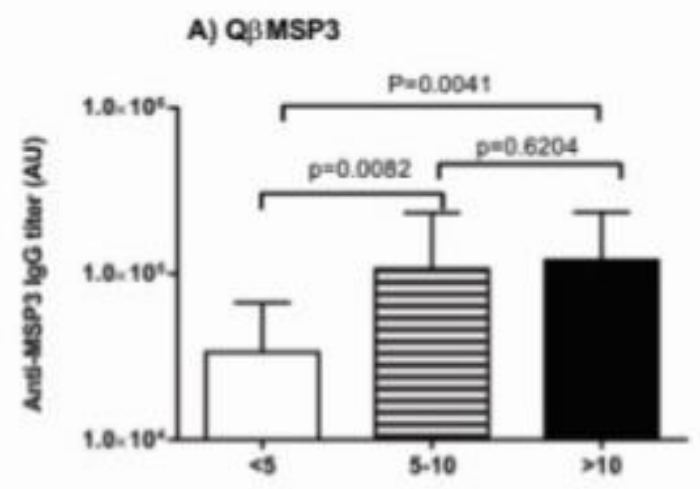

B) Q8 UB05

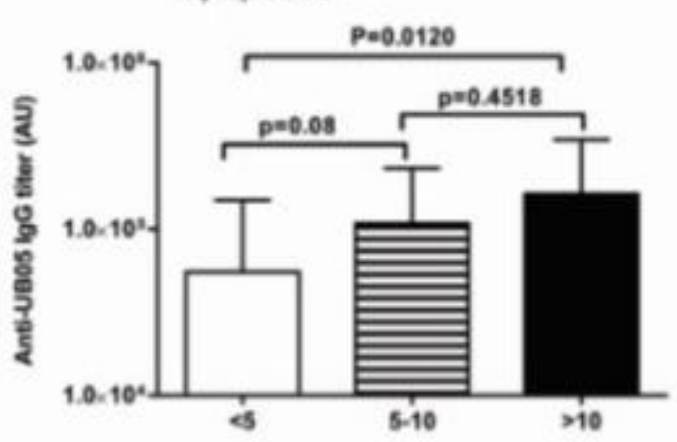

C) QpuBos-MSp3

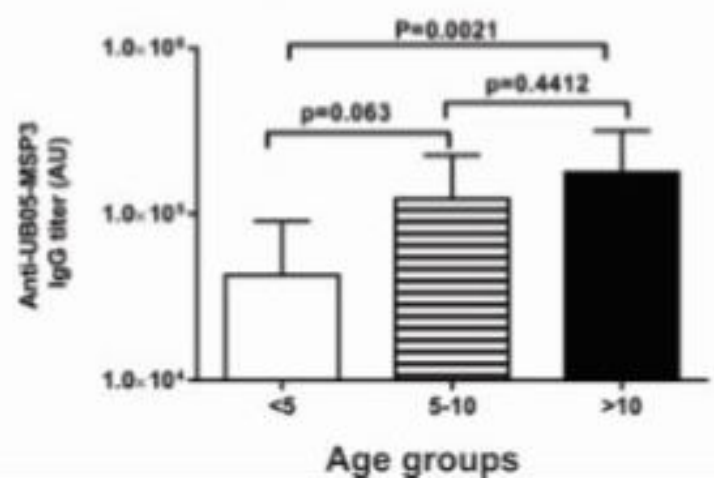

Figure 5: Antigenicity of the recombinant phages Q $\beta M S P 3$, $\mathrm{Q} \beta \mathrm{UB} 05$ and $\mathrm{Q} \beta \mathrm{UB} 05 \mathrm{MSP} 3$ in plasma from malaria positive children. Plasma of malaria positive participants was tested for reactivity with the different recombinant phages including $\mathrm{Q} \beta \mathrm{MSP} 3, \mathrm{Q} \beta \mathrm{UB} 05$ and $\mathrm{Q} \beta \mathrm{UB} 05 \mathrm{MSP} 3$. In (A) data is shown for the reactivity of the recombinant phage $\mathrm{Q} \beta \mathrm{MSP} 3$ with children grouped according to different age groups. In (B) and (C) same as in (A) but here the antigens used were recombinant $\mathrm{Q} \beta \mathrm{UB} 05$ and Q $\beta$ UB05MSP3 respectively. Here, plasma of all children older than five years were significantly more reactive with recombinant phages $(\mathrm{P}<0.01)$ than samples from children less than 5 years old.
Ease of production allows cheap and rapid scale up for large scale production. $\mathrm{Q} \beta$ is attractive as a vaccine vector because recombinant $\mathrm{Q} \beta$ is devoid of bacteriophage genetic information and is neither infectious nor capable of replicating. Moreover during recombinant gene expression E.coli RNA which is potent TLR7/8 ligands gets packaged in the phage particles and thus could activate the immune system. In addition to efficient immune-stimulatory properties $Q \beta$ recombinant phage display has a number of desirable features for vaccine development including stability, safety, rapid and cheap manufacture.

However here we wanted to test whether antigenicity of both MSP3 and UB05 could be further improved by genetically incorporating them as a chimera upon the surface of $\mathrm{Q} \beta$. The recombinant phage Q $\beta$ UB05-MSP3 was tested side by side with both Q $\beta U B 05$ and $\mathrm{Q} \beta \mathrm{MSP} 3$ for their antigenicity in plasma from children living in a high malaria transmission region of Cameroon. In a comparative analysis of the recognition of the recombinant phages Q $\beta$ UB05, Q $\beta M S P 3$ and Q $\beta$ UB05-MSP3; we observed for both malaria positive and negative children greater levels of antigen-specific IgG antibodies in the plasma of those older than 10 years relative to children less than five years. Antibody levels in plasma of 5-10 years old malaria negative children was also significantly higher $(\mathrm{p}=0.045)$ for the recombinant phages Q $\beta$ UB05-MSP3 relative to their counterpart less than 5 years old. This implies that Q $\beta$ UB05-MSP3 could be used not only to track antibody levels in children but can be a potential vaccine candidate for boosting such responses in these children.

People with naturally acquired immunity to malaria produce antibodies specific to several parasite antigens which have been demonstrated to play a role in their resistance to clinical disease and parasitaemia [14,24,32,37]. In this regards protective immunity mediated especially by asexual blood stage antigens like MSP3 or UB05 could either mean just the absence of symptomatic malaria but underlying parasitaemia or the complete absence of both symptomatic malaria and parasitaemia. In this study most of children diagnosed positive for malaria by point of care kit and microscopy were all parasitaemic without clinical symptoms. This is probably due to the fact that participants were from a high malaria transmission region where people including children can gain protection from severe disease early on in life as a result of frequent exposure to the malaria parasite. High concentrations of antibodies specific to a number of asexual blood stage antigens including MSP1-3, AMA-1, UB05, MSP3 have been associated with protective immunity against malaria [38]. However this may not always be true as in children in Mali the number of antigens recognized was more relevant in protection than antibody titers [32].

In this study children less than five years irrespective of their malaria status showed significantly less anigen specific antibody levels than their counterparts older than five years. This is probably due to age linked limitted exposure to the malaria parasite comparared to older children who probably must have experienced far more exposures. However no clear cut distinction could be made between protective immune responses to malaria and those resulting from exposure to the parasite during clinical malaria. In both malaria positive and negative participants, antibody levels increased concurrently with age probably as a result of accumulating antibody responses to different circulating Plasmodium falciparum strains within this high malaria transmision zone as previously reported for other regions. 
Citation: Waffo AB, Lissom A, Ouambo HF, Ngu LN, Ngoh AA, et al. (2018) Surface Engineering of the RNA Coliphage Q $\beta$ to Display Plasmodium Falciparum Derived Asexual Blood Stage Antigens UB05 and Merozoite Surface Protein 3. Clin Microbiol 7: 314. doi: $10.4172 / 2327-5073.1000314$

Page 9 of 10

\section{Conclusion}

The recombinant Q $\beta M S P 3$, Q $\beta$ UB05 and Q $\beta$ UB05-MSP3 phages presented here were antigenic for monoclonal antibodies targeting their $\mathrm{N}$ and $\mathrm{C}$-terminal regions respectively. They all differentially detected blood stage antigen targeting antibodies in children below and above five years old. Thus designing and validating novel approaches for the study of human malaria especially in children who are the most susceptible in high transmission zones could usher in new management strategies that would limit mortality and morbidity.

\section{Ethics Approval and Consent to Participate}

This study received ethical approval from the Cameroon National Ethics Committee for Human Health Research (Reference numbers 2015/03/561/CE/CNERSH/SP and 2018/01969/CE/CNERSH/SP) and the CIRCB institutional review board (protocol number 14-11). All participants provided written informed consent. Data were processed using specific identifiers for privacy and confidentiality purposes. Clinical data generated during the course of this study was provided free of charge to all participants.

\section{Availability of Data and Materials}

All data are fully available without restriction. Data are available from the CIRCB Institutional Data Access/Ethics Committee for researchers who meet the criteria for access to confidential data. All request for Data should be addressed to the director General of CIRCB reachable by the following address:

Prof. Alexis Ndjolo

Director General CIRCB

BP 3077 Messa Yaounde Cameroon

Tel. +237222315450

Fax. +237222315456

E-mail: andjolo@yahoo.com or andjolo@circb-cm

\section{Competing Interests}

The authors have declared that no competing interests exist.

\section{Funding}

This project was funded by grants from CIRCB, EDCTP (grant \#TA. 2010.40200.016) TWAS (\#12059RG/bio/af/ac_G) and Canada grand challenge (\#0121-01); to Godwin W Nchinda; from Korea-Africa cooperation grant (NRF-2013K1A3A1A09076155) from the National Research Foundation of Korea funded by the Ministry of Science, ICT and Future Planning in the Republic of Korea to Chae Gyu Park; and then from the Center for NanoBiotechnology Research (CNBR) of ASU for grant \#NSF-CREST (HRD-241701) and grant \#NSF-AGEP (1432991 BKR) of National Science Foundation to Alain Bopda Waffo.

\section{Author Contributions}

Conceived and designed the experiments: G.W.N and A.B.W

Performed the experiments: A.L, O.F.H, C.A.S, A.A.N, L.N.N, G. A, A.S.O, S.B, F.T.T, G.D.N.P, A.G, R.G and D.T
Technical assistance: J.C.T, R.M, C.A.S, C.G.P, L.N.N, G.O.C, E.A.A, W.M, L.K, D.N, J.N.C.A, C.O.E

Analyzed the data: G.W.N, A.B.W, A.L

Wrote the paper: A.L, G.W.N and A.B.W

\section{Acknowledgement}

The authors are grateful to Professor Weber for $\mathrm{pBRT7Q} \beta$, and to Professor Alexander Chetverin for $\mathrm{pQ} \beta 7$ and $\mathrm{pQ} \beta 8$ plasmids. We thank all volunteers who consented to participate in this study. We would like to thank the personnel of unites techniques of CIRCB for their help in collecting the blood samples.

\section{References}

1. Crompton PD, Pierce SK, Miller LH (2010) Advances and challenges in malaria vaccine development. J Clin Invest 120: 4168-4178.

2. Wondji CS, Coleman M, Kleinschmidt I, Mzilahowa T, Irving H, et al. (2012) Impact of pyrethroid resistance on operational malaria control in Malawi. Proc Natl Acad Sci USA 109: 19063-19070.

3. Mohapatra PK, Sarma DK, Prakash A, Bora K, Ahmed MA, et al. (2014) Molecular evidence of increased resistance to anti-folate drugs in Plasmodium falciparum in North-East India: a signal for potential failure of artemisinin plus sulphadoxine-pyrimethamine combination therapy. PLoS One 9: e105562.

4. Harrington WE, Mutabingwa TK, Muehlenbachs A, Sorensen B, Bolla $\mathrm{MC}$, et al. (2009) Competitive facilitation of drug-resistant Plasmodium falciparum malaria parasites in pregnant women who receive preventive treatment. Proc Natl Acad Sci USA 106: 9027-9032.

5. Olotu A, Fegan G, Wambua J, Nyangweso G, Leach A, et al. (2016) SevenYear Efficacy of RTS,S/AS01 Malaria Vaccine among Young African Children. N Engl J Med 374: 2519-2529.

6. Agnandji ST, Lell B, Soulanoudjingar SS, Fernandes JF, Abossolo BP, et al. (2011) First results of phase 3 trial of RTS,S/AS01 malaria vaccine in African children. N Engl J Med 365: 1863-1875.

7. Gosling R, von Seidlein L (2016) The Future of the RTS,S/AS01 Malaria Vaccine: An Alternative Development Plan. PLoS Med 13: e1001994.

8. MVI PMViP, GSK G (2015) Fact sheet: The RTS,S malaria vaccine candidate (MosquirixTM).

9. Cohen S, Mc GI, Carrington S (1961) Gamma-globulin and acquired immunity to human malaria. Nature 192: 733-737.

10. Chiu CYH, Healer J, Thompson JK, Chen L, Kaul A, et al. (2014) Association of antibodies to Plasmodium falciparum reticulocyte binding protein homolog 5 with protection from clinical malaria. Front Microbiol 5: 314.

11. Nazareth R, Horumpende P, Sonda T, Ndaro A, Mollel E, et al. (2017) Naturally Acquired Antibody Responses to a Synthetic Malaria Antigen AS202.11. J Tropic Med 6843701: 1-5.

12. Richards JS, Arumugam TU, Reiling L, Healer J, Hodder AN, et al. (2013) Identification and prioritization of merozoite antigens as targets of protective human immunity to Plasmodium falciparum malaria for vaccine and biomarker development. J Immunol 191: 795-809.

13. Richards JS, Beeson JG (2009) The future for blood-stage vaccines against malaria. Immunol Cell Biol 87: 377-390.

14. Titanji VP, Amambua-Ngwa A, Anong DN, Mbandi SK, Tangie E, et al. (2009) Isolation and expression of UB05, a Plasmodium falciparum antigen recognised by antibodies from semi-immune adults in a high transmission endemic area of the Cameroonian rainforest. Clin Chem Lab Med 47: 1147-1158.

15. Anong DN, Fru-Cho J, Mbandi KS, Amambua NA, Nkuo-Akenji T, et al. (2016) Expression pattern of immunoglobulin G subclasses in response to UB05 antigen in a Plasmodium falciparum endemic area in Cameroon. Iss Biologic Sci Pharmaceut Res 4: 11-16. 
Citation: Waffo AB, Lissom A, Ouambo HF, Ngu LN, Ngoh AA, et al. (2018) Surface Engineering of the RNA Coliphage Q $\beta$ to Display Plasmodium Falciparum Derived Asexual Blood Stage Antigens UB05 and Merozoite Surface Protein 3. Clin Microbiol 7: 314 . doi: $10.4172 / 2327-5073.1000314$

Page 10 of 10

16. Fowkes FJ, Richards JS, Simpson JA, Beeson JG (2010) The relationship between anti-merozoite antibodies and incidence of Plasmodium falciparum malaria: A systematic review and meta-analysis. PLoS Med 7: e1000218.

17. Sirima SB, Cousens S, Druilhe P (2011) Protection against malaria by MSP3 candidate vaccine. N Engl J Med 365: 1062-1064.

18. Singh S, Soe S, Mejia JP, Roussilhon C, Theisen M, et al. (2004) Identification of a conserved region of Plasmodium falciparum MSP3 targeted by biologically active antibodies to improve vaccine design. J Infect Dis 190: 1010-1018.

19. Roussilhon C, Oeuvray C, Muller-Graf C, Tall A, Rogier C, et al. (2007) Long-term clinical protection from falciparum malaria is strongly associated with IgG3 antibodies to merozoite surface protein 3. PLoS Med 4: e320.

20. Soe S, Theisen M, Roussilhon C, Aye KS, Druilhe P (2004) Association between protection against clinical malaria and antibodies to merozoite surface antigens in an area of hyperendemicity in Myanmar: complementarity between responses to merozoite surface protein 3 and the 220-kilodalton glutamate-rich protein. Infect Immun 72: 247-252.

21. McColl DJ, Anders RF (1997) Conservation of structural motifs and antigenic diversity in the Plasmodium falciparum merozoite surface protein-3 (MSP-3). Mol Biochem Parasitol 90: 21-31.

22. Huber W, Felger I, Matile H, Lipps HJ, Steiger S, et al. (1997) Limited sequence polymorphism in the Plasmodium falciparum merozoite surface protein 3. Mol Biochem Parasitol 87: 231-234.

23. Oeuvray C, Bouharoun-Tayoun H, Gras-Masse H, Bottius E, Kaidoh T, et al. (1994) Merozoite surface protein-3: a malaria protein inducing antibodies that promote Plasmodium falciparum killing by cooperation with blood monocytes. Blood 84: 1594-1602.

24. Dinga JN, Njimoh DL, Kiawa B, Djikeng A, Nyasa RB, et al. (2016) Differential T-cell responses to a chimeric Plasmodium falciparum antigen; UB05-09, correlates with acquired immunity to malaria. Parasite Immunol 38: 303-316.

25. Dinga JN, Gamua SD, Ghogomu SM, Titanji VPK (2018) Preclinical efficacy and immunogenicity assessment to show that a chimeric Plasmodium falciparum UB05-09 antigen could be a malaria vaccine candidate. Parasite Immunol 40.

26. Shi Q, Lynch MM, Romero M, Burns JM Jr, (2007) Enhanced protection against malaria by a chimeric merozoite surface protein vaccine. Infect Immun 75: 1349-1358.
27. Bang G, Prieur E, Roussilhon C, Druilhe P (2011) Pre-clinical assessment of novel multivalent MSP3 malaria vaccine constructs. PLoS One 6: e28165.

28. Sirima SB, Tiono AB, Ouedraogo A, Diarra A, Ouedraogo AL, et al. (2009) Safety and immunogenicity of the malaria vaccine candidate MSP3 long synthetic peptide in 12-24 months-old Burkinabe children. PLoS One 4: e7549.

29. Waffo AB, Ngu LN, Singleton RL, Egbo T, Simo JL, et al. (2017) Surface Engineering of Recombinant RNA Coliphage $Q \beta$ to Display gp41 MembraneProximal External-Region Epitopes from HIV-1. J Clin Exp Immunol 2: 1-15.

30. Waffo AB (2004) Evolutionary RNA-coliphage $Q \beta$ \{Q-beta\} Display: Expression Biopathway in E. Coli. Cuvillier.

31. Skamel C, Aller SG, Bopda Waffo A (2014) In vitro evolution and affinity-maturation with Coliphage qbeta display. PLoS One 9: e113069.

32. Daou M, Kouriba B, Ouedraogo N, Diarra I, Arama C, et al. (2015) Protection of Malian children from clinical malaria is associated with recognition of multiple antigens. Malar J 14: 56.

33. Blokhina EA, Kuprianov VV, Stepanova LA, Tsybalova LM, Kiselev OI, et al. (2013) A molecular assembly system for presentation of antigens on the surface of $\mathrm{HBc}$ virus-like particles. Virology 435: 293-300.

34. Yin Z, Gildersleeve J, Finn Mg, Huang X (2014) Developing bacteriophage $\mathrm{Q} \beta$ as versatile carrier for anti-carbohydrate cancer vaccine: influence of antigen design on antibody responses (VAC8P.998). J Immunol 192: 142-144.

35. Khan F, Porter M, Schwenk R, DeBot M, Saudan P, et al. (2015) Head-toHead Comparison of Soluble vs. Qbeta VLP Circumsporozoite Protein Vaccines Reveals Selective Enhancement of NANP Repeat Responses. PLoS One 10: e0142035.

36. Leneghan DB, Miura K, Taylor IJ, Li Y, Jin J, et al. (2017) Nanoassembly routes stimulate conflicting antibody quantity and quality for transmission-blocking malaria vaccines. Sci Rep 7: 3811.

37. Doolan DL, Dobano C, Baird JK (2009) Acquired immunity to malaria. Clin Microbiol Rev 22: 13-36.

38. Murungi LM, Kamuyu G, Lowe B, Bejon P, Theisen M, et al. (2013) A threshold concentration of anti-merozoite antibodies is required for protection from clinical episodes of malaria. Vaccine 31: 3936-3942. 